\title{
Utilization of Sewage Sludge in the Manufacturing of Lightweight Aggregates: A Review
}

\author{
Rajen J. Patel ${ }^{1}$, Prof. (Mrs) Reshma L. Patel ${ }^{2}$, Dr. Jayeshkumar Pitroda ${ }^{3^{*}}$ \\ ${ }^{I}$ Final year M. Tech. Student, Environmental Engineering, B.V.M. Engineering college, Vallabh Vidyanagar, \\ Gujarat, India. \\ ${ }^{2}$ Associate Professor, Civil Engineering Department, B.V.M. Engineering college, Vallabh Vidyanagar, \\ Gujarat, India. \\ ${ }^{3}$ Assistant Professor, Civil Engineering Department, B.V.M. Engineering college, Vallabh Vidyanagar, \\ Gujarat, India.
}

*Corresponding Author: Dr. Jayeshkumar Pitroda, Assistant Professor, Civil Engineering Department, B.V.M. Engineering college, Vallabh Vidyanagar, Gujarat, India.

\begin{abstract}
Sewage sludge management is one of the major environmental issues these days. Sewage sludge is generated from the sewage treatment plants, and this by product is something that is not going to stop getting produced. As a result, it has become extremely important to manage this sewage sludge in a proper well defined manner. One of the best alternatives for managing this sludge is to use it as a raw material in some other industry. In this paper, we will review various papers on the use of sewage sludge as a raw material. The effects of using sewage sludge as a raw material in making lightweight aggregates is reviewed in this paper.
\end{abstract}

Keywords: Eco-Friendly, Lightweight Aggregates, Sewage Sludge, Environmental Issues

\section{INTRODUCTION}

Sewage Sludge can be defined as a material that is obtained as a by-product in sewage treatment plants. The main source of sewage sludge is the human community. It is produced because of our day to day activities. So, there is no doubt that there will be any reduction in the produced sewage sludge.

Classes of treated sewage sludge:

1. Class A sludge is dried and pasteurized and known as exceptional sludge.

2. Class B sludge includes undigested sludge.

Also nowadays, we are experiencing population expansion, which will eventually lead to the increased amount of sewage sludge to be dealt with. Few of the most common method used for dealing with sewage sludge are landfilling, incineration, using as a raw material, and so on.

Among these methods, landfilling is normally used. The main problem with this method is the availability of land for dumping of sludge. With the problem of increasing population at our door step, it is quite difficult to get some spare land for sewage disposal these days. Also, disposal of sewage sludge by incineration is not so much economical and also it requires brand new technology for its success.

This is the reason; management of sewage sludge has become a very important issue these days. Lots of research work is going on in this sector to find a desirable alternative for disposal. That is where; the third method of sewage sludge management comes into picture, which is, use of sewage sludge as a raw material.

If we use sewage sludge as a raw material, it will relieve us from the trouble of managing that sewage sludge; because that sludge is being already used up as a raw material.

\section{Critical Literature RevieW}

Following are the critical literature reviews on papers of eco-friendly brick production using different type of industrial solid waste: 
Wainwright et al. (2002) described a newly developed rotary kiln for the production of synthetic aggregates from a variety of wastes. The main waste used is quarry fines mixed with paper sludge, clay or dredged harbor sediments. Results showed that compressive strength of concrete made using this aggregates at 28 days interval was well beyond desired limit which proves this aggregates are reliable to be used in concrete work.[32]

T.W. Cheng et al. (2003) studied the production of $\mathrm{CaO}-\mathrm{A} 12 \mathrm{O} 3-\mathrm{SiO} 2$ system glass ceramics of incinerator fly ash prepared by vitrification and then heat treated in different conditions. Treated samples in general showed good leachability characteristics and also chemical durability with an exception in the $\mathrm{HCl}$ solution. For both processes, higher temperature treatments showed crystal growth; hence poor properties were attained. Good physical and mechanical properties achieved at the heat treatment temperature of 900-950 degree $C$ in this study prove that the treated samples have attractive potential for engineering applications. [36]

Samad et al. (2004) investigated the bricks produced from sewage sludge for various sludge proportions. Results showed that quantity of sludge is the key factor which determines the brick quality. It was also found that with the increase in the quantity of sludge added, water absorption of bricks increases. At $10 \%$ by wt of sludge, density of brick was $2.43 \mathrm{~g} / \mathrm{cm}^{\wedge} 3$ which reduced to 0.33 $\mathrm{g} / \mathrm{cm}^{\wedge} 3$ for $40 \%$ by wt of sludge. This downward trend was due to the associative loss of water and organic matter from the sludge in the bricks when treated by firing in the kiln. Sludge addition in the range of $10 \%$ to $40 \%$ by wt was considered to be suitable for brick production as per the results. [1]

Cheeseman et al. (2005)studied the production of LWA from incinerator bottom ash, and study the physical and leaching properties of the same. Lightweight aggregates with densities, water absorption and crushing strength as good as commercially available aggregates are obtained. Hence, it is feasible to use IBA for the manufacturing of LWA.[8]

M.M. Jordán et al. (2005) studied the application of sewage sludge in the manufacturing of ceramic tile body. Clay was substituted by sewage sludge in different proportions in ceramic body. Results showed that with the increase in sludge proportion, water absorption increases.[19]

P. A. Bingham et al. (2006) studied vitrification of ashes collected from the incineration of municipal solid waste (MSW) and sewage sludge from the point of view of their composition, glass melting and reuse potential. The main reason leading to vitrification is the landfill cost. Although the technical challenges related with vitrifying wastes have been met, the economic and social issues related with waste separation remain a significant issue to the large scale adoption of vitrification for dealing with hazardous wastes.[31]

Ramamurthy et al. (2006) studied the effect of three binders namely, cement, lime and bentonite on the properties of sintered fly ash aggregates. It can be seen that water absorption in sintered fly ash aggregates without binders is about $21 \%-22 \%$. Water absorption seems to reduce with the addition of lime as binder. Cement performs better than lime in reducing water absorption. With the addition of $20 \%$ bentonite, water absorption reduced to $15 \%-16 \%$. Also, addition of $20 \%$ bentonite results in optimal strength and minimum water absorption.[16]

Fakhfakh et al. (2007) studied the effect of addition of sand on the lightweight aggregates production. Twelve Tunisian smectite-rich claystone-marlstones were studied. The addition of quartz sand by $15 \%$ found to give better expansion properties to some of the aggregates. On the other hand, addition of $1 \%$ of used automobile oil to clay and quartz sand mixture, found to form more gas and drop in bloating temperature. It was found that the addition of quartz sand was necessary to avoid LWAsexplosion and to eliminate thermal pre-treatment. Approximate quartz addition required was about $15 \%$. Also, addition of sand caused some changes in the porosity of the aggregates; numerous interconnected pores were observed in the core of the aggregates. While addition of used automobile oil showed variable results. Pore size increased considerably with no change in firing temperature. When sand was added, water absorption increased to $25 \%$, and this value rose to $50 \%$ with the addition of oil.[10]

Meng-Feng Hung et al. (2007) investigated the recycling of the fine sediments of Shih-Men Reservoir to make lightweight aggregates. The particle density of sintered lightweight aggregate decreases as the sintering temperature increases above $1200^{\circ} \mathrm{C}$ due to phase transformation and formation of a vitrified layer on the surface. Fine sediment from Shin-Men Reservoir prove to be 
suitable raw material for manufacturing expanded lightweight aggregate at temperatures in the range of 1200 to $1300^{\circ} \mathrm{C}$ and sintering time of 10 to 12 minutes. [27]

D. Fytili et al. (2008) presented past and future approaches in sludge handling, mainly focused at thermal processes and the utilization of sewage sludge in cement manufacturing. As per the paper, agricultural use is considered to be insecure. In case of incineration scrubbing cost of produced gases is more. Therefore, the alternative methods such as pyrolysis, wet oxidation, etc have definite advantages over previously mentioned methods. [9]

Guoren et al. (2009) investigated the stabilization of heavy metals in ceramsite made from waste water treatment sludge and drinking water treatment sludge. The study implied that the heavy metals in the ceramsite are stable and will not cause any secondary pollution. WWTS and DWTS can be used as a harmful ceramsite and it solves the problem of sludge management. [12]

M.A. Montero et al. (2009) studied the effect of addition of marble sludge and urban sewage sludge to clay in ceramic body. Bending strength of the ceramic tile body met the standard requirement when the sludge content is kept at $16 \%$ to $22 \%$ of the clay. Hence, it was found that addition of these residues is a convenient way of sludge management, but care should be taken to use it in a controlled manner. [18]

M. Rodas et al. (2009) studied the lightweight aggregates produced from mining and industrial wastes. Lightweight aggregates were manufactured using 50\% washing aggregate sludge and 50\% clay-rich sediment was studied. Only aggregates with this proportion showed expansion. The expansion mainly depends on the formation and release of gases. LWAs with the lowest bulk density and dry particle density are produced with $75 \%$ sewage sludge and $25 \%$ washing aggregate sludge.[6]

Min Yue et al. (2010) studied the characteristics of ultra lightweight aggregates prepared from dehydrated sewage sludge. From the studies, optimum conditions for the production of ULWC was found to be as, $25 \%-35 \%$ addition of DSS, preheating temperature of $400{ }^{\circ} \mathrm{C}$ for 20 minutes and sintering into electric furnace at $1150{ }^{\circ} \mathrm{C}$ for 10 minutes. [39]

Chao-Wei Tang et al. (2011) studied the lightweight aggregates prepared from fine sediment deposits dredged from the Shihmen River in Taiwan. Result shows that particle density of LWA prepared is 1010 to $1380 \mathrm{~kg} / \mathrm{m} 3$, quite lower than the normal aggregate. Also, 28-days compressive strength of LWA concrete meets the strength requirements for structural light weight concrete. Hence, manufacturing LWA aggregates from fine river sediments is feasible. [9]

Wojciech et al. (2011) studied the use of spent glauconite in the production of lightweight aggregates. Results showed that the use of glauconite for removal of zinc ions is a feasible approach. Also, use of spentglauconite as an additive increases the porosity of the aggregates. [39]

Joan et al. (2012) studied the environmental suitability of using sewage sludge for making clay bricks, by carrying out leachability and toxicity studies. From the study, it can be said that sludge can be successfully used into bricks with quantity in the range of 5\%-25\% by weight, higher than this would result in insufficient mechanical properties. Leaching tests suggest that there are no environmental restrictions on the use of clay bricks made from either of the sludge. [16]

Angelo et al. (2012) examines the potential use of fly ash in the production of lightweight aggregates. It is found that good quality of lightweight aggregates can be produced with fly ash with high free lime content. Also, the concrete produced from this LWA meets the standard requirements. [4]

J.Monzó et al. (2012) studied the effect of reusing of sewage sludge pellets (SSP) obtained from drying sludge process and sewage sludge ash (SSA) obtained from incineration of wastewater sludge, in building materials manufacturing. Experimental results indicated the feasibility of the partial replacement of cement by 15 and $30 \%$ by SSA in mortars. [14]

Min Yue et al. (2012) examined the chemical, thermal and toxic properties of dried sewage sludge (DSS), the production and characteristics of lightweight sludge ceramic (LSC) produced and the process of action of the organic and inorganic foaming agents. Preparation lightweight sludge ceramics (LSC) by sintering sludge added to clay was found to be favorable. The addition of DSS lowered the rate of expansion of the clay ceramic pellets. When the DSS dosage was above50 wt\%, 
the body of the LSC showed shrinkage. The heavy metal concentrations released from LSC are much lower than the levels stated in environmental regulations.[29]

Malgorzata et al. (2012) studied the basic physical and mechanical properties of lightweight aggregates produced from sewage sludge and clay. Aggregates obtained were of apparent density of $0.812 \mathrm{~g} / \mathrm{cm} 3$ and bulk density of $0.415 \mathrm{~g} / \mathrm{cm} 3$, water absorption of $16.2 \%$, porosity of $40 \%$, void content of $52 \%$, no coloring compounds. This result shows that light weight aggregates modified with MSW can be used for the production of light weight concrete. [23]

Guangyin et al. (2013) studied the ways to reuse dewatered sludge and municipal incineration bottom ash. Results showed that DS and MSWI bottom ash both can be used for the production of controlled low strength materials. Leaching test revealed that leachable substances in the leachate are quite less and the product formed is environmentally friendly. [12]

Bui Le et al. (2014) studied the potential of lightweight aggregates produced from wastes and its application in lightweight concrete. LWA were prepared from wet sewage sludge and reservoir sediments, and was used as coarse aggregates in preparing lightweight concrete. The unit weight of concrete prepared by using LWA as coarse aggregates reduced more than $18 \%$, which results in considerable weight loss. Also, the compressive strength is in the desirable limit. Hence, the use of reservoir sediment showed a positive effect on the overall properties of LWA and also on lightweight concrete. [7]

Na Wei et al. (2015) studied the stability of heavy metals in lightweight aggregates made from sewage sludge and MSWI fly ash. Various ratios of MSWI fly ash and sewage sludge were tried and leaching test was conducted for these ratios. Also, leaching test was conducted for various sintering temperature and sintering time. From the test results, it was found that the optimal MSWI fly ash and sewage sludge ratio, sintering temperature and sintering time are $2.8,1100{ }^{\circ} \mathrm{C}$ and 8 minutes respectively. [31]

Malgorzata et al. (2016) studied the properties of Lightweight aggregates modified by the addition of used motor oil. $1 \%$ to $2 \%$ of motor oil addition showed maximum porosity in the LWA. With the increase in the proportion of motor oil beyond this limit, decrease in porosity is observed. Mineral composition of LWA does not depend on oil addition and also not on zeolitic admixtures. [25]

Malgorzata et al. (2016) studied the use of sewage sludge in the production of lightweight aggregates. Mixture of sewage sludge and clay was used to prepare lightweight aggregates. Two samples were made as per their sintering temperature, $1100{ }^{\circ} \mathrm{C}$ and $1150{ }^{\circ} \mathrm{C}$ respectively. Both the prepared aggregates were than compared with commercially available aggregates. It was found that the prepared aggregates were lighter than commercial aggregates and, also with increase in sintering temperature porosity of aggregate increases. In other words, aggregate with higher sintering temperature is lighter. A part from this, compounds formed in the aggregates were those available in nature and hence, there is no risk of leaching of heavy metals from the prepared aggregates. [22]

B. Gonzalez et al. (2016) studied microstructure and mineralogy of lightweight aggregates prepared from washing sludge, sewage sludge and clay rich sediment. Eight different types of lightweight aggregates with different Sewage sludge, washing sludge and clay rich sediment proportions were formed and studied. From the study, following relationships can be formed: Microstructure - bloating index, Microstructure - dry particle density, Mineralogy - dry particle density, Microstructure - water absorption, Mineralogy - water absorption, Microstructure - crushing strength and Mineralogy crushing strength.[5]

Mingwei et al. (2017) investigated the effect of mass ratio $(\mathrm{K})$ of basic and acidic oxides on lightweight aggregates. Results showed that when $\mathrm{K}$ was kept at 0.2 , it resulted in the formation of LWA with maximum compressive strength of $17.07 \mathrm{MPa}$. Also, it became evident from the results that with the $\mathrm{K}$ value in the range of $0.15-0.3$, LWA aggregates of high quality can be obtained. [30]

Pao-Ter et al. (2016) investigated the recycling of electric arc furnace slag waste into heavy duty green ceramic tiles. Results showed that as weight percentage of EAF slag increases up to $60 \%$ by wt, the percentage of apparent porosity and water absorption increases too, with a reduction in tile flexural strength and increased porosity. [34]

The following table 1 shows the literature review papers and its comparison. 
Table1. Literature review papers and its comparison

\begin{tabular}{|c|c|c|c|c|c|c|}
\hline Author & Year & $\begin{array}{c}\text { Utilization } \\
\text { Area }\end{array}$ & $\begin{array}{l}\text { Material } \\
\text { Used }\end{array}$ & $\begin{array}{c}\text { Addition/ } \\
\text { Replacement }\end{array}$ & Tests & $\begin{array}{l}\text { Increase/ } \\
\text { Desirable }\end{array}$ \\
\hline Mingwei & 2017 & $\begin{array}{l}\text { Lightweight } \\
\text { Aggregates }\end{array}$ & sewage sludge & Replacement & Compressive strength & Desirable \\
\hline Pao-Ter & 2016 & $\begin{array}{l}\text { Green Ceramic } \\
\text { Tiles }\end{array}$ & $\begin{array}{l}\text { Electric Arc Furnace } \\
\text { Slag }\end{array}$ & Addition & Water Absorption & Increases \\
\hline B.Gonzalez & 2016 & $\begin{array}{l}\text { Lightweight } \\
\text { Aggregates }\end{array}$ & $\begin{array}{l}\text { Sewage } \\
\text { Sludge }\end{array}$ & Replacement & Compressive strength & Desirable \\
\hline Małgorzata & 2016 & $\begin{array}{l}\text { Lightweight } \\
\text { Aggregates }\end{array}$ & $\begin{array}{l}\text { Sewage } \\
\text { Sludge }\end{array}$ & Replacement & $\begin{array}{l}\text { Particle density } \\
\text { Water Absorption }\end{array}$ & $\begin{array}{l}\text { Desirable } \\
\text { Desirable }\end{array}$ \\
\hline Małgorzata & 2016 & $\begin{array}{l}\text { Lightweight } \\
\text { Aggregates }\end{array}$ & Used Motor Oil & Addition & Microtomography & Desirable \\
\hline Na Wei & 2015 & $\begin{array}{l}\text { Lightweight } \\
\text { Aggregates }\end{array}$ & $\begin{array}{l}\text { Sewage } \\
\text { Sludge and MSWI fly } \\
\text { ash }\end{array}$ & Replacement & Leaching test & Desirable \\
\hline Bui Le & 2014 & $\begin{array}{l}\text { Lightweight } \\
\text { Aggregates }\end{array}$ & $\begin{array}{l}\text { Sewage } \\
\text { Sludge }\end{array}$ & Replacement & Unit Weight & Decreases \\
\hline Guangyin & 2013 & $\begin{array}{l}\text { Lightweight } \\
\text { Aggregates }\end{array}$ & $\begin{array}{l}\text { Dewatered Sludge and } \\
\text { MSWI bottom ash }\end{array}$ & Replacement & Leaching test & Decreases \\
\hline Małgorzata & 2012 & $\begin{array}{l}\text { Lightweight } \\
\text { aggregates }\end{array}$ & $\begin{array}{l}\text { Sewage Sludge and } \\
\text { Clay }\end{array}$ & Replacement & $\begin{array}{l}\text { Water absorption and } \\
\text { porosity }\end{array}$ & Desirable \\
\hline MinYue & 2012 & \begin{tabular}{|l|} 
Lightweight \\
ceramics
\end{tabular} & Dried Sewage Sludge & Addition & Leaching test & Desirable \\
\hline J.Monzó & 2012 & $\begin{array}{l}\text { Sewage Sludge } \\
\text { Pellets }\end{array}$ & Sewage Sludge Ash & Replacement & Feasibility & Desirable \\
\hline Angelo & 2012 & $\begin{array}{l}\text { Lightweight } \\
\text { Aggregates }\end{array}$ & Fly Ash & Replacement & Feasibility & Desirable \\
\hline Joan & 2012 & Clay Brick & Sewage Sludge & Replacement & Leaching test & Desirable \\
\hline Wojciech & 2011 & $\begin{array}{l}\text { Lightweight } \\
\text { Aggregates }\end{array}$ & Spent Glauconite & Replacement & Porosity & Increases \\
\hline $\begin{array}{l}\text { Chao-Wei } \\
\text { Tang }\end{array}$ & 2011 & $\begin{array}{l}\text { Lightweight } \\
\text { Aggregates }\end{array}$ & Sediment Deposit & Replacement & Particle Density & Decreases \\
\hline Chee Ming & 2011 & Clay Brunt Brick & Natural Fibre & Addition & $\begin{array}{l}\text { Compressive } \\
\text { Strength } \\
\end{array}$ & Desirable \\
\hline
\end{tabular}

\section{CONClusion}

Based on literature review the following conclusions are drawn:

- Sewage Sludge is used as an effective raw material for the production of various construction materials.

- Using sewage sludge as a raw material will help to solve the most critical problem the world is facing these days i.e. sewage sludge management.

- This will eventually lead to the conservation of our natural resources. Because manufacturing of aggregates by conventional method leads to the destruction of our natural topographical features.

- LWAs with the lowest bulk density and dry particle density are produced with sewage sludge and washing aggregate sludge.

- Use of sewage sludge for the manufacturing of various materials provides us with the materials with desirable physical and mineralogical properties.

- The lightweight aggregates produced showed lowest leachability. Most of the metals found in the aggregates were stable and hence safe to be used.

\section{ACKNOWLEDGEMENT}

The Authors thankfully acknowledge to Dr. C. L. Patel, Chairman, Charutar Vidya Mandal, and Er. V. M. Patel, Hon. Jt. Secretary, Charutar Vidya Mandal, Prof. (Dr.) Indrajit Patel, Principal, B.V.M. Engineering College, Vallabh Vidyanagar, Gujarat, India for their motivations and infrastructural support to carry out this research. 


\section{REFERENCES}

[1] Abdul G. LiewAzniIdris Abdul A. Samad Calvin H.K.WongMohd S. JaafarAminuddin M. Baki (2004), "Reusability of sewage sludge in clay bricks", J Mater Cycles Waste Manag, Volume 6, 41-47

[2] Alaa.A.Shakir, SivakumarNaganathan, Kamal Nasharuddin Bin Mustapha (2013), "Development of Bricks From Waste Material: A Review Paper", Australian Journal of Basic and Applied Sciences, Volume 7, Issue 8, 812-818

[3] AndreyBagreev, Teresa J. Bandosz(2004), "Efficient Hydrogen Sulfide Adsorbents Obtained by Pyrolysis of Sewage Sludge Derived Fertilizer Modified with Spent Mineral Oil”, Environmental Science \& Technology, American Chemical Society, , Volume 38, Issue 1, 345-351

[4] Angelo Sarabèr, Robert Overhof, Terry Green, Jan Pels (2012), "Artificial lightweight aggregates as utilization for future ashes - A case study", Waste Management, Volume 32, 144-152

[5] B. Gonzalez-Corrochano, J. Alonso-Azcarate, M. Rodas, J.E Barrenechea, EJ. Luque (2016), "Microstructure and mineralogy of lightweight aggregates manufactured from mining and industrial wastes"

[6] B. Gonza'lez-Corrochano, J. Alonso-Azca'rate, M. Rodas (2009), "Production of lightweight aggregates from mining and industrial wastes", Journal of Environmental Management, Volume 90, 2801-2812

[7] Bui Le Anh Tuan; MewaelGebregiorgisTesfamariam; Yuan-Yuan Chen; Chao-Lung Hwang; Kae-Long Lin; and Mung-Pei Young (2014), "Production of Lightweight Aggregate from Sewage Sludge and Reservoir Sediment for High-Flowing Concrete", J. Construction Engineering and Management, Volume $140,1-7$

[8] C.R. Cheeseman, A. Makinde, S. Bethanis (2005), "Properties of lightweight aggregate produced by rapid sintering of incinerator bottom ash", Resources Conservation and Recycling, Elsevier, Volume 43, 147162

[9] Chao-Wei Tang, How-Ji Chen, Shun-Yuan Wang, Jack Spaulding (2011), "Production of synthetic lightweight aggregate using reservoir sediments for concrete and masonry", Cement \& Concrete Composites, Volume: 33, 292-300

[10] D. Fytili, A. Zabaniotou (2008), "Utilization of sewage sludge in EU application of old and new methods-A review", Renewable and Sustainable Energy Reviews, Volume 12, 116-140

[11] E. Fakhfakh, W. Hajjaji, M. Medhioub, F. Rocha, A. López-Galindo, M. Setti, F. Kooli, F. Zargouni, F. Jamoussi (2007), "Effects of sand addition on production of lightweight aggregates from Tunisian smectite-rich clayey rocks",Proceedings of ECOpole, Volume 35, 228-237

[12] Guangyin Zhen, Xueqin Lu, Youcai Zhao, Jing Niu, Xiaoli Chai, LianghuSu,Yu-You Li, Yuan Liu, Jingru Du, ToshimasaHojo, Yong Hu (2013), "Characterization of controlled low-strength material obtained from dewatered sludge and refuse incineration bottom ash: Mechanical and microstructural perspectives", Journal of Environmental Management, Volume 129, 183-189

[13] GuorenXu, JinlongZou, Guibai Li (2009),"Stabilization/Solidification of Heavy Metals in Sludge Ceramsite and Leachability Affected by Oxide Substances", Environmental Science and Technology, Volume 43, 5902-5907

[14] J.Monzó, J.Payá, M.V.Borrachero, J.J.Morenilla, M. Bonilla, P. Calderón1 (2012), "Some Strategies for Reusing Residues from Waste Water Treatment Plants: Preparation of Binding Materials"

[15] J.M. Magalhães, J.E. Silva, F.P. Castro, J.A. Labrincha (2004), "Effect of experimental variables on the inertization of galvanic sludges in clay-based ceramics", Journal of Hazardous Materials, Volume 106B, $139-147$

[16] Joan A. Cusidó, Lázaro V. Cremades (2012), "Environmental effects of using clay bricks produced with sewage sludge: Leachability and toxicity studies”, Waste Management, Elsevier, Volume 32, 1202-1208

[17] K. Ramamurthy, K.I. Harikrishnan (2006), "Influence of binders on properties of sintered fly ash aggregate", Cement \& Concrete Composites, Volume 28, 33-38

[18] M. Ahmaruzzaman (2011), "Industrial wastes as low-cost potential adsorbents for the treatment of wastewater laden with heavy metals", Advances in Colloid and Interface Science, Elsevier, Volume 166, 36-59

[19] M.A. Montero, M.M. Jordán, M.S. Hernández-Crespo, T. Sanfeliu (2009), "The use of sewage sludge and marble residues in the manufacture of ceramic tile bodies", Applied Clay Science, Volume 46, 404-408

[20] M.M. Jordán, M.B. Almendro-Candel, M. Romero, J.Ma. Rincón (2005), “Application of sewage sludge in the manufacturing of ceramic tile bodies", Waste Applied Clay Science, Volume 30, 219-224

[21] Magdalena WdowinMałgorzataFranusRafałPanek Lidia BaduraWojciechFranus (2014), "The conversion technology of fly ash into zeolites", Clean Techn Environ Policy, Volume 16, 1217-1223 
[22] MałgorzataFranus, DanutaBarnat-Hunek, Magdalena Wdowin (2016), "Utilization of sewage sludge in the manufacture of lightweight aggregate", Environ Monit Assess, Springer, Volume 188, Issue 10, 01-13

[23] MałgorzataFranus,DanutaBarnat-Hunek(2012), "Analysis of Physical and Mechanical Properties of Lightweight Aggregate Modified with Sewage Sludge”,Proceedings of ECOpole, Volume 9, Issue 1, 3339

[24] Małgorzata Franus1, and Lidia Bandura (2014), "Sorption of Heavy Metal Ions from Aqueous Solution by Glauconite", Fresenius Environmental Bulletin, Volume 23, Issue 3a, 825 - 839

[25] MałgorzataFranus, GrzegorzJozefaciuk, Lidia Bandura, Krzysztof Lamorski, MieczysławHajnos and WojciechFranus (2016), "Modification of Lightweight Aggregates' Microstructure by Used Motor Oil Addition”, MDPI, Volume 9, ISSUE 845, 02-12

[26] Małgorzata Franus1, and Lidia Bandura (2014), "Sorption of Heavy Metal Ions from Aqueous Solution by Glauconite", Fresenius Environmental Bulletin, Volume 23, Issue 3a, 825 - 839

[27] Markd. Ho, Gregj Evans(2000), "Sequential Extraction of Metal Contaminated Soils with Radiochemical Assessment of Readsorption Effects”, Environmental Science Technology, Volume 34, 1030-1035

[28] Meng-Feng Hung and Chao-Lung Hwang (2007), "Study of fine sediments for making lightweight aggregate", Waste Management \& Research, Volume 25, 449-456

[29] Min YUE, Qinyan YUE, Yuanfeng QI, Baoyu GAO, Hui YU (2012), "Properties and effect of forming sewage sludge into lightweight ceramics", Front Environmental Science Engineering, Higher Education Press and Springer-Verlag Berlin Heidelberg, Volume 6, Issue 1, 117-124

[30] Mingwei Liu, GuorenXu, Guibai Li (2017), "Effect of the ratio of components on the characteristics of lightweight aggregate made from sewage sludge and river sediment", Process Safety and Environmental Protection, Volume 10 5, 109-116

[31] Na Wei (2015), "Leachability of Heavy Metals from Lightweight Aggregates Made with Sewage Sludge and Municipal Solid Waste Incineration Fly Ash", International Journal of Environmental Research and Public Health, Volume 12, 4992-5005

[32] P. A. Bingham and R. J. Hand (2006)," Vitrification of toxic wastes: a brief review", Maney, Volume 105 , Issue 1, 21-31

[33] P. J. Wainwright, D. J. F. Cresswell, H. A. van der Sloot (2002), “The production of synthetic aggregate from a quarry waste using an innovative style rotary kiln”, Waste Management \& Research, Volume 20, 279-289

[34] Pao-TerTeo, Anasyida Abu Seman, ProjjalBasu, NurulakmalMohd Sharif (2014), "Recycling of Malaysia's electric arc furnace (EAF) slag waste into heavy-duty green ceramic tile", Waste Management, $1-12$

[35] Sebastian Werle, Ryszard K. Wilk (2010), "A review of methods for the thermal utilization of sewage sludge:The Polish perspective”, Renewable Energy, Volume 35, 1914-1919

[36] Stefan Rubli, Edi Medilanski, HasanBelevi(2000), "Characterization of Total Organic Carbon in Solid Residues Provides Insight into Sludge Incineration Processes", Environmental Science and Technology, Volume 34, 1772-1777

[37] T.W. Cheng, Y.S. Chen (2003), "On formation of $\mathrm{CaO}-\mathrm{Al}_{2} \mathrm{O}_{3}-\mathrm{SiO}_{2}$ glass-ceramics by vitrification of incinerator fly ash", Chemosphere, Pergamon, Volume 51, 817-824

[38] WojciechFranus, Magdalena Wdowin,MałgorzataFranus (2014), "Synthesis and characterization of zeolites prepared from industrial fly ash”, Environ Monit Assess, Volume 186, 5721-5729

[39] WojciechFranus, MałgorzataFranus, JolantaLatosińska, RafałWójcik (2011), "The use of spent glauconite in lightweight aggregate production”, Boletín de la Sociedad Española de Cerámica y Vidrio, Volume 50, Issue 4, 193-200

[40] Yuanfeng Qi, QinyanYue, Shuxin Han, Min Yue, BaoyuGao, Hui Yu, Tian Shao (2010), "Preparation and mechanism of ultra-lightweight ceramics produced from sewage sludge", Journal of Hazardous Materials, Volume 176, 76-84 


\section{AUTHORS' BIOGRAPHY}

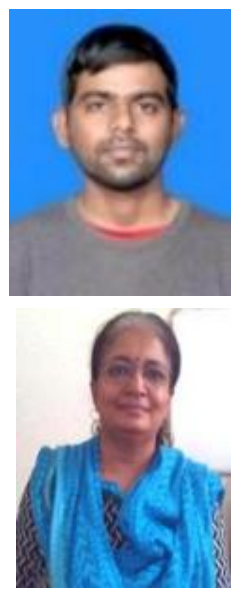

Rajen J. Patel, received his Bachelor of Engineering degree in Civil Engineering from the Maharaja Sayajirao University, Vadodara, Gujarat in 2013. At present, he is a final year student of Master's Degree in Environmental Engineering from Birla Vishvakarma Mahavidyalaya, Gujarat Technological University.

Years in the field of Research, Designing and education. She is guiding M.E. (Environmental Engineering) Thesis work in the field of Civil/ Environmental Engineering. She has published many papers in National/ International Conferences and International Journals.

Prof. Reshma L. Patel, received her Bachelor of Engineering degree in Civil Engineering from the Birla Vishvakarma Mahavidyalaya, Sardar Patel University in 1991. In 1993 she received her Master's Degree in Civil (Environmental) Engineering from Birla Vishvakarma Mahavidyalaya, Sardar Patel University. She joined Birla Vishvakarma Mahavidyalaya Engineering College as a faculty in 1994, where she is Associate Professor of Civil Engineering Department with a total experience of 22

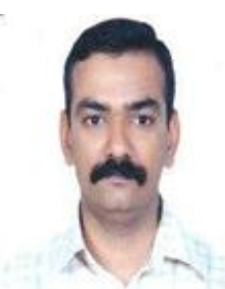

Dr. Jayeshkumar R Pitroda, received his bachelor of engineering degree in Civil Engineering from Birla Vishwakarma Mahavidyalaya Engineering College, Sardar Patel University in 2000. In 2009 he received his master's degree in Construction Engineering and Management from Birla Vishwakarma Mahavidyalaya Sardar Patel University. In 2015 he received his Doctor of philosophy (Ph.D.) degree in Civil Engineering from Sardar Patel University. He joined Birla Vishwakarma Mahavidyalaya Engineering College as a faculty in 2009, where he is Assistant Professor of Civil Engineering Department with a total experience of 17 years in the field of research, designing, and education. He is guiding M.E./M.Tech. (Construction Engineering and Management/ Environmental Engineering) thesis work in the field of Civil / Construction Engineering. He has published many papers in National / International Conferences and International Journals. He has published nine Research Books in the field of Civil Engineering, Rural Road Construction, National Highways Construction, Utilization of Industrial Waste, Fly Ash Bricks, Construction Engineering and Management, Eco-friendly Construction.

Citation: R. J. Patel et.al., "Utilization of Sewage Sludge in the Manufacturing of Lightweight Aggregates: A Review", International Journal of Constructive Research in Civil Engineering, 4(2), pp. 7-14. DOI: http://dx. doi.org/10.20431/2454-8693.0402002

Copyright: () 2018 R. J. Patel, et.al.,. This is an open-access article distributed under the terms of the Creative Commons Attribution License, which permits unrestricted use, distribution, and reproduction in any medium, provided the original author and source are credited. 